\title{
Activation of astroglial calcium signaling by endogenous metabolites succinate and gamma-hydroxybutyrate in the nucleus accumbens
}

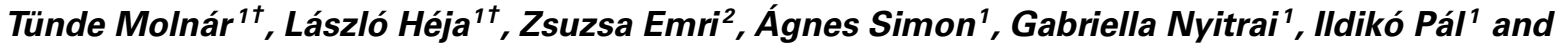 \\ Julianna Kardos ${ }^{1 *}$
}

${ }^{1}$ Department of Neurochemistry, Chemical Research Center, Hungarian Academy of Sciences, Budapest, Hungary

2 Department of Zoology, Eszterházy Károly College, Eger, Hungary

Edited by:

Yuri Zilberter, INSERM U751, France

Reviewed by:

Alexej Verkhratsky, University of Manchester, UK

Mortimer Mamelak, University of

Toronto, Canada

\section{*Correspondence:}

Julianna Kardos, Department of

Neurochemistry, Chemical Research

Center, Hungarian Academy of

Sciences, Pusztaszeri út 59-67, 1025

Budapest, Hungary.

e-mail: jkardos@chemres.hu

‘Tünde Molnár and László Héja have contributed equally to this work.
Accumulating evidence suggests that different energy metabolites play a role not only in neuronal but also in glial signaling. Recently, astroglial $\mathrm{Ca}^{2+}$ transients evoked by the major citric acid cycle metabolite succinate (SUC) and gamma-hydroxybutyrate (GHB) that enters the citric acid cycle via SUC have been described in the brain reward area, the nucleus accumbens (NAc). Cells responding to SUC by $\mathrm{Ca}^{2+}$ transient constitute a subset of ATPresponsive astrocytes that are activated in a neuron-independent way. In this study we show that GHB-evoked $\mathrm{Ca}^{2+}$ transients were also found to constitute a subset of ATPresponsive astrocytes in the NAc. Repetitive $\mathrm{Ca}^{2+}$ dynamics evoked by GHB suggested that $\mathrm{Ca}^{2+}$ was released from internal stores. Similarly to SUC, the GHB response was also characterized by an effective concentration of $50 \mu \mathrm{M}$. We observed that the number of ATPresponsive cells decreased with increasing concentration of either SUC or GHB. Moreover, the concentration dependence of the number of ATP-responsive cells were highly identical as a function of both [SUC] and [GHB], suggesting a mutual receptor for SUC and GHB, therefore implying the existence of a distinct GHB-recognizing astroglial SUC receptor in the brain. The SUC-evoked $\mathrm{Ca}^{2+}$ signal remained in mice lacking $\mathrm{GABA}_{B}$ receptor type 1 subunit in the presence and absence of the $N$-Methyl-d-Aspartate (NMDA) receptor antagonist (2R)-amino-5-phosphonovaleric acid (APV), indicating action mechanisms independent of the $\mathrm{GABA}_{B}$ or NMDA receptor subtypes. By molecular docking calculations we found that residues R99, H103, R252, and R281 of the binding crevice of the kidney SUC-responsive membrane receptor SUCNR1 (GPCR91) also predict interaction with GHB, further implying similar GHB and SUC action mechanisms. We conclude that the astroglial action of SUC and GHB may represent a link between brain energy states and $\mathrm{Ca}^{2+}$ signaling in astrocytic networks.

Keywords: energy metabolites, succinate, gamma-hydroxybutyrate, astroglial calcium signaling, nucleus accumbens

\section{INTRODUCTION}

Using $\mathrm{Ca}^{2+}$ imaging in combination with immunohistochemistry, we have recently demonstrated significant co-localization of ATPstimulated $\mathrm{Ca}^{2+}$ bursts with the glial marker protein connexin 43 $(\mathrm{Cx} 43)$ in slices containing the brain reward area (Berridge and Kringelbach, 2008), the nucleus accumbens (NAc) of juvenile rats (Molnár et al., 2011). Store-dependent $\mathrm{Ca}^{2+}$ bursting triggered by ATP was significantly reduced by an antibody raised against the $\mathrm{Cx} 43$ carboxy-terminal segment and by gap junction inhibitors such as carbenoxolone hemisuccinate (CBX) and flufenamic acid as well as the purinergic G protein-coupled receptor (GPCR) P2 $\mathrm{Y}_{1}$ subtype-selective antagonist MRS2179, but not by blocking neuronal activity with tetrodotoxin. The effect of MRS2179 implied that intercellular $\mathrm{Ca}^{2+}$ signaling was triggered by the activation of $\mathrm{P}_{2} \mathrm{Y}_{1}$ receptors. Neurons within the domain of ATP-activated astrocytes did not show $\mathrm{Ca}^{2+}$ transients and exhibited invariant postsynaptic currents (Molnár et al., 2011). We also observed for the first time the activation of repetitive astroglial $\mathrm{Ca}^{2+}$ transients in response to the major intermediate of the citric acids cycle succinic acid (SUC). The apparent $\mathrm{EC}_{50}(50-60 \mu \mathrm{M})$ of SUC effect is within the range of physiological plasma SUC concentration (Molnár et al., 2011), since the concentration of SUC in plasma increases from 5 up to $125 \mu \mathrm{M}$ with exercise, metabolic acidosis or hyperglycemic metabolic states (Krebs, 1950; Nordmann and Nordmann, 1961; Hochachka and Dressendorfer, 1976; Kushnir et al., 2001; Forni et al., 2005; Sadagopan et al., 2007). These data suggest that SUC-responsive $\mathrm{Ca}^{2+}$ transients may also have a regulatory role for cellular energy supply. SUC-responsive cells also participated in the ATP induced concerted $\mathrm{Ca}^{2+}$ bursts (Molnár et al., 2011). These findings conclusively suggest that astroglial $\mathrm{Ca}^{2+}$ bursting evoked by SUC couples astroglial activation to cerebral energy resources.

A common binding site for SUC and gamma-hydroxybutyrate (GHB), that enters the citric acid cycle via SUC (Rumigny et al., 
1981) has been disclosed previously (Molnár et al., 2006, 2008a,b). Additionally, intracellular $\mathrm{Ca}^{2+}$ store-reliant astroglial $\mathrm{Ca}^{2+}$ transients evoked by GHB have been described in the NAc (Molnár et al., 2009). We have shown that this action of $\mathrm{GHB}$ is $\mathrm{GABA}_{\mathrm{B}}$ receptor independent, since it remains in mice lacking functional $\mathrm{GABA}_{\mathrm{B}}$ receptors unlike the majority of GHB-mediated physiological and pharmacological actions including "rape drug effects" that were demonstrated to be dependent on $\mathrm{GABA}_{\mathrm{B}}$ receptors (Kaupmann et al., 2003; Wong et al., 2004). Only a few study addressed GHB receptor dependent GHB actions (Molnár et al., 2006, 2009), although high-affinity GHB binding sites were demonstrated in mice lacking $\mathrm{GABA}_{\mathrm{B}}$ receptors (Kaupmann et al., 2003) and the function of endogenous GHB has never been clearly defined. A number of studies indicate that in addition to its neurotransmitter/neuromodulatory role, GHB may function in the control of physiological states, like sleep and hibernation. Moreover, it is an endogenous protective agent when tissue energy supplies are limited (MacMillan, 1980a,b; Mamelak, 1989; references cited). The molecular identity of the GHB receptor has not been identified yet satisfactorily, the putative GHB receptor mRNA showed different brain distribution than the native GHB receptors (Andriamampandry et al., 2003, 2007). A binding site recognizing GHB and SUC has been disclosed in the NAc (Molnár et al., 2006, 2008a,b), its relationship with the G protein-coupled heptahelical kidney SUC receptor (SUCNR1:GPCR91, He et al., 2004) has not previously been conjectured.

ATP induced functional coupling of $\mathrm{Cx} 43$ hemichannels is known to evoke store-mediated repetitive $\mathrm{Ca}^{2+}$ transients triggered by activation of purinergic GPCRs in vitro (Stout et al., 2002; Anderson et al., 2004; Beierlein and Regehr, 2006; Piet and Jahr, 2007) and in vivo (Hirase et al., 2004; Takata and Hirase, 2008; Hoogland and Kuhn, 2010; Hoogland et al., 2009; Nimmerjahn, 2009; Nimmerjahn et al., 2009). Different in vitro paradigms, including locally administered ATP stimuli $(100 \mu \mathrm{M})$ were found effective (Barry and Cheek, 1994; Li et al., 2001; Zur Nieden and Deitmer, 2006; D'Ascenzo et al., 2007; Fischer et al., 2009). In awake, behaving animal, three types of glial $\mathrm{Ca}^{2+}$-excitation were distinguishable according to the number of networking cells and the dependence on neuronal stimulation (Nimmerjahn et al., 2009): flares (involving large networks of astrocyte fibers), sparkles (restricted to individual fibers), and bursts (expanding radial waves). Spontaneous bursting can be contrasted to sparks and flares as being independent of neuronal activity (Nimmerjahn et al., 2009). Thus, the question may also come up, how ATP-responsive glial $\mathrm{Ca}^{2+}$ bursting proceeds and what functions it perform in cellular communication?

In order to better understand these issues, we used different models and/or approaches to compare the effects of GHB with those of SUC and/or ATP: (i) rat brain slice containing the NAc studied by combined application of confocal $\mathrm{Ca}^{2+}$ imaging and $\mathrm{Cx} 43$ immunohistochemistry to explore and compare GHB-responsive and ATP puff-evoked astroglial $\mathrm{Ca}^{2+}$ bursting; (ii) evaluation of SUC/GHB- and ATP-evoked $\mathrm{Ca}^{2+}$ transients to disclose mechanistic clues; (iii) homology model of SUCNR1 (He et al., 2004) to simulate binding interactions between SUC/GHB and SUCNR1; (iv) slices containing the NAc from mice lacking $\mathrm{GABA}_{\mathrm{B}}$ receptor type 1 subunit in combination with confocal
$\mathrm{Ca}^{2+}$ imaging to distinguish SUC-responsive $\mathrm{Ca}^{2+}$ transients and to compare with $\mathrm{GHB}$-evoked $\mathrm{Ca}^{2+}$ signals (Molnár et al., 2009). We report on astroglial $\mathrm{Ca}^{2+}$ bursting linked to endogenous metabolites GHB and SUC performing similar function that might possibly be related to cellular energy states.

\section{MATERIALS AND METHODS BUFFERS AND TEST COMPOUNDS}

Slice preparing buffer contained in mM: 250 sucrose, $2 \mathrm{KCl}, 1.25$ $\mathrm{KH}_{2} \mathrm{PO}_{4}, 10 \mathrm{MgSO}_{4}, 2 \mathrm{CaCl}_{2}, 16 \mathrm{NaH}_{2} \mathrm{CO}_{3}$, and 10 glucose. Artificial cerebrospinal fluid (ACSF) contained in mM: $129 \mathrm{NaCl}, 2 \mathrm{KCl}$, $1.25 \mathrm{KH}_{2} \mathrm{PO}_{4}, 1 \mathrm{MgSO}_{4}, 2 \mathrm{CaCl}_{2}, 16 \mathrm{NaHCO}_{3}$, and 10 glucose.

The following drugs, applied via the ACSF perfusion including SUC, GHB, and adenosine 5'-triphosphate disodium salt (ATP) were obtained from Sigma-Aldrich (Budapest, Hungary). Fluorescence indicators Fluo-4 acetoxymethyl ester (Fluo-4 AM) was purchased from Molecular Probes (Eugene, OR, USA). Stock solutions of ester fluorescence indicators prepared in DMSO were diluted to $0.2 \%$ DMSO in the staining solution.

\section{ANIMALS}

Animal care and preparation were in accordance with the Helsinki declaration, European Council Directive of 24 November 1986 (86/609/EEC), Hungarian Animal Act 1998 and associated institutional guidelines, as approved by the local authority. BALB/c $\mathrm{GABA}_{\mathrm{B} 1}(-/-)$ mice exhibit spontaneous seizures (Prosser et al., 2001; Schuler et al., 2001) thus BALB/c GABA B1 $_{1}(-/+)$ mice were bred, their offspring genotyped at the seventh day and used by the tenth day before seizure could develop in $(-/-)$ mice. All efforts were made to minimize animal suffering and the number of animals used.

\section{ACUTE SLICE PREPARATION AND DYE-LOADING}

Coronal slices from the forebrain containing the NAc and the caudate putamen $(\mathrm{CP})$ were prepared for the imaging experiments. Ten to 14-day-old male Wistar rats or 10 day-old mice were decapitated and the forebrain blocks were sliced into $300 \mu \mathrm{m}$ thin coronal slices by a vibratome (Vibratome, Technical Products International Inc., St. Louis, MO, USA) in ice-cold preparation buffer. Slices were incubated for $1 \mathrm{~h}$ under humidified gas-mixture carbogen $(5 \%$ $\left.\mathrm{CO}_{2}+95 \% \mathrm{O}_{2}\right)$ atmosphere in an interface-type holding chamber containing warmed $\left(35^{\circ} \mathrm{C}\right) \mathrm{ACSF}$. After preincubation in $2 \%$ pluronic acid containing ACSF for $2 \mathrm{~min}$, slices were incubated with $5 \mu \mathrm{M}$ Fluo- $4 \mathrm{AM}$ in ACSF for $1 \mathrm{~h}$ at $35^{\circ} \mathrm{C}$ in the dark under humidified carbogen $\left(5 \% \mathrm{CO}_{2}+95 \% \mathrm{O}_{2}\right)$ atmosphere (Molnár et al., 2009). In order to monitor cell death, several slices were exposed to double dye-loading protocol, performed by adding $7.5 \mu \mathrm{M}$ propidium iodide (PI excitation: $534 \mathrm{~nm}$, emission: 570 $600 \mathrm{~nm}$ ) to the Fluo-4 AM containing ACSF. In order to allow for cleavage of the AM ester group of Fluo-4, slices were transferred to dye-free ACSF at least $30 \mathrm{~min}$ before the start of the experiment (Porter and McCarthy, 1996).

\section{CONFOCAL IMAGING AND DRUG TESTING PROTOCOL}

Fluorescence recordings of changes in the intracellular $\mathrm{Ca}^{2+}$ ion level in cells loaded with Fluo-4 AM were performed as described (Molnár et al., 2009) with an upright epifluorescent 
microscope (Olympus BX61WI, Olympus, Budapest, Hungary) equipped with the FluoView300 confocal laser-scanning system (Olympus, Budapest, Hungary) using $20 \times$ (0.5 numerical aperture $)$ or $60 \times(0.9$ numerical aperture $)$ water immersion objectives. Image acquisition rate was controlled by a computer running FluoView 5.0 software (Olympus, Budapest, Hungary).

Freshly isolated slices were transferred to the submerge-type recording chamber mounted on the stage of the microscope and were superfused with carbogenated $\left(5 \% \mathrm{CO}_{2}+95 \% \mathrm{O}_{2}\right)$ ACSF ( $3 \mathrm{ml} / \mathrm{min}$, room temperature). Serial scanning of slices were made at $488 \mathrm{~nm}$ excitation wavelength and emitted green fluorescence was collected through a $510-530 \mathrm{~nm}$ bandpass filter. $\mathrm{Ca}^{2+}$ transients were initiated by application of SUC or GHB in the perfusion or by pressure-ejection of $100 \mu \mathrm{M}$ ATP in ACSF through a glass micropipette $(5-10 \mu \mathrm{M}$ diameter) on the slice surface. Fluorescence intensity changes within a $355 \mu \mathrm{m} \times 355 \mu \mathrm{m}$ field containing approximately 100 Fluo-4 AM loaded cells around the area of the ATP puff, were followed over a 10-min interval ( 2 s/image).

Two 10-min-long recordings were made from each slice with a 20-min resting time between the two recordings. ATP was applied $3 \mathrm{~min}$ after the beginning of each 10-min-long recording period. The cells showing $\mathrm{Ca}^{2+}$ increase after ATP applications at approximately $15-30 \mu \mathrm{m}$ below the surface were counted (approximately 45 cells in response to the ATP stimulus) and fluorescence changes of cells that responded to ATP applications were measured. The observation threshold was $5 \times$ of the variance of the baseline fluorescence.

$N$ denotes the number of slices in a given experimental condition. Statistical analysis was performed using the non-parametric Mann-Whitney test with Bonferroni post hoc test (OriginLab Corporation, Northampton, UK) and $p<0.05$ was considered statistically significant. Unless otherwise stated, the effects of different treatments were compared to the control. Images recorded by the FluoView300 software were processed using the free ImageJ 1.41 image analysis software (http://rsbweb.nih.gov/ij/).

\section{POST-CALCIUM IMAGING IMMUNOHISTOCHEMISTRY PROTOCOL FOR CX43 AND GFAP}

In order to identify the cell types involved in $\mathrm{Ca}^{2+}$ bursts, we followed our recently described protocol (Molnár et al., 2011). The brain slices were immunostained with antibodies for astrocyte marker proteins (Cx43 and GFAP). However, Fluo-4 signal could not be preserved through fixation with either $0.4 \%$ paraformaldehyde or $40 \mathrm{mg} / \mathrm{ml}$ EDAC (1-ethyl-3-(3-dimethylaminopropyl)carbodiimide, Sigma-Aldrich). Therefore co-localization between SUC/ATP-responsive cells and cell type markers could not be resolved. Hence we opted to perform the in situ immunostaining in non-fixed slices directly after the $\mathrm{Ca}^{2+}$ imaging protocol. Slices used previously to measure $\mathrm{Ca}^{2+}$ changes in response to SUC/ATP application were treated as follows: upon completion of the calcium-imaging experiments, each slice was kept in its original position in the recording chamber (using a ballast) and incubated with Cx43 (1:300) and GFAP (1:200) primary antibodies for $30 \mathrm{~min}$, at room temperature. After $3 \mathrm{~min} \times 10 \mathrm{~min}$ washing in ACSF, the slice was incubated with Chromeo 546 goat antirabbit (1:100 Abcam, Cambridge, UK, catalog number: ab60317) secondary antibody and Alexa-488 donkey anti-mouse (1:100,
Molecular Probes) secondary antibody in ACSF for $30 \mathrm{~min}$ at room temperature. This was followed by $3 \times 10 \mathrm{~min}$ washing in ACSF. Serial Z-scans of Cx43 - (excitation: $543 \mathrm{~nm}$, emission: 570-600 nm) and GFAP - (excitation: $488 \mathrm{~nm}$, emission: 510$530 \mathrm{~nm}$ ) labeled slices were acquired between the slice surface and the maximal penetration depth of the antibodies (approximately $60-70 \mu \mathrm{m}$ from the surface) through a $20 \times$ objective $(1 \mu \mathrm{m} / \mathrm{step})$. Since the fluorescence emission of both Fluo- 4 and Alexa-488 dyes are collected in the 510-530 $\mathrm{nm}$ range, GFAP-specific staining was obtained by subtracting the Fluo-4 fluorescence from the GFAP immunolabeling signal at each $\mathrm{Z}$ depth. Optical sections from identical depths of Fluo- 4 and $\mathrm{Cx} 43$ images were merged along the $\mathrm{Z}$ axis. Single cells, glia filaments, or blood vessels that showed double immunolabeling were recorded through a $60 \times$ objective and Z-scans were performed by alternating the excitation wavelengths between $543 \mathrm{~nm}$ (Cx43) and $488 \mathrm{~m}$ (GFAP) using FluoView 5.0 software at each depth $(0.1 \mu \mathrm{m} / \mathrm{step})$. Images were processed using ImageJ 1.41 and Adobe Photoshop 8.0 image analysis softwares.

\section{SIMULATIONS}

The sequence of the human kidney SUC receptor1 (SUCNR1; accession code: Q9BXA5) was downloaded from the UniprotKB database. The SUCNR1 receptor model was built based on the bovine rhodopsin (RHO) structure (PDB code 1f88; Palczewski et al., 2000). The alignment was adopted from He et al. (2004), with one manual adjustment: Asn253 of SUCNR1 was aligned to Ala269 of RHO by reducing the five residue gap of $\mathrm{He}$ et al. (2004). The alignment continued according to He et al. (2004), from and Ser275 of SUCNR1, and Ile286 of RHO. The model was built by Modeller9v3 (Sali and Blundell, 1993), and prepared in SYBYL8.0 (Tripos Inc., St. Louis, MO, USA). Hydrogen atoms were added to the protein, and chains were terminated by $N$-methyl and acetyl groups by the Analyze Protein menu of the Biopolymer module. His103 was protonated at both $N$ atoms, corresponding to an acidic environment. SUC and GHB ligands were prepared from the PDB database (SUC ligand of 2WBP; Helmetag et al., 2009) in their protonated form according to the acidic $\mathrm{pH}$ of the receptor binding (Molnár et al., 2006, 2008a,b). Ligands were minimized in SYBYL until the RMS gradient reached $0.01 \mathrm{kcal} / \mathrm{mol} / \AA \AA$. Docking was performed by GOLD5.1 (Cambridge Crystallographic Data Center). A cavity of $10 \AA$ was searched in the docking studies containing the predicted binding crevice residues of SUCNR1 (Arg99, His103, Arg252, Arg281), see Figure 4 GoldScore was used for evaluating the results. Figures were prepared by Pymol.

\section{RESULTS}

\section{GHB-RESPONSIVE CELLS CONSTITUTE A SUB-POPULATION OF ASTROCYTES RESPONDING TO ATP}

As outlined in the Section "Introduction," we tested the hypothesis that similarly to SUC (Molnár et al., 2011), GHB also acts on a subpopulation of ATP-responsive cells. Indeed, the presence of GHB $(50 \mu \mathrm{M})$ in the superfusion evoked $\mathrm{Ca}^{2+}$ transients (Figure 1A), covering some astroglial $\mathrm{Ca}^{2+}$ bursts occurred in response to the ATP puff $(100 \mu \mathrm{M}$, Figure 1B, see also Movie S1 in Supplementary Material). The ATP-evoked $\mathrm{Ca}^{2+}$ signal propagated circularly 


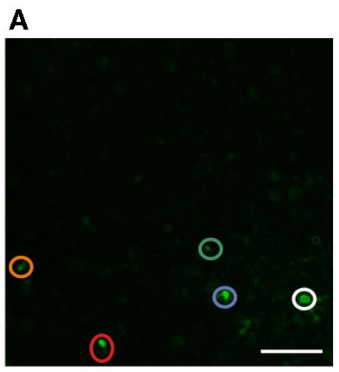

D

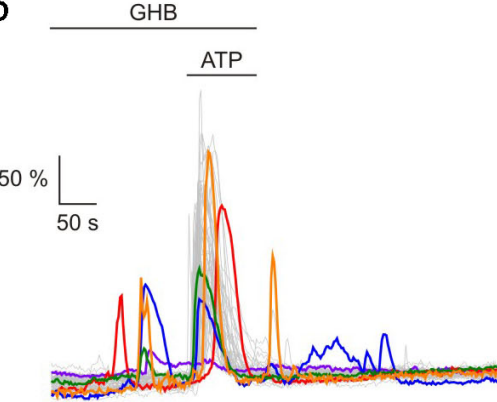

FIGURE 1 | GHB and ATP evoke overlaying $\mathrm{Ca}^{2+}$ transients in the rat NAc slice. Representative confocal image of GHB-responsive cells [(A) circled] participated in ATP-stimulated concerted $\mathrm{Ca}^{2+}$ burst [(B) circled]. Arrow indicates the direction of the superfusion buffer. Arrowhead indicates the location and direction of the ATP puff. Scale bar is $50 \mu \mathrm{m}$. (C) Pseudo-color depiction of the spatiotemporal characteristics of the astroglial $\mathrm{Ca}^{2+}$ transients evoked by GHB and ATP shown in (B) (see also Movie S1 in Supplementary
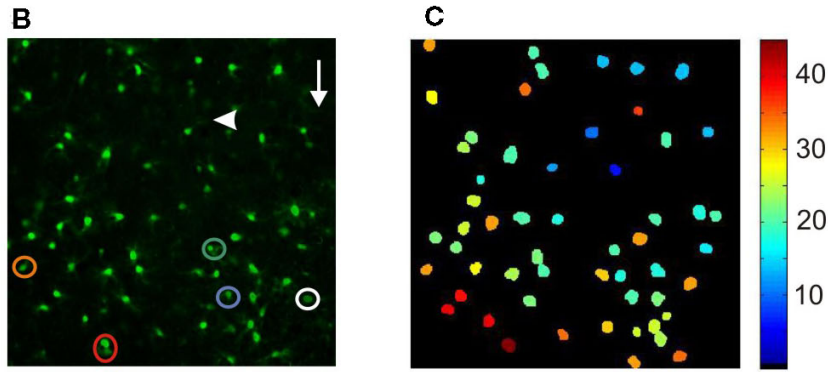

E

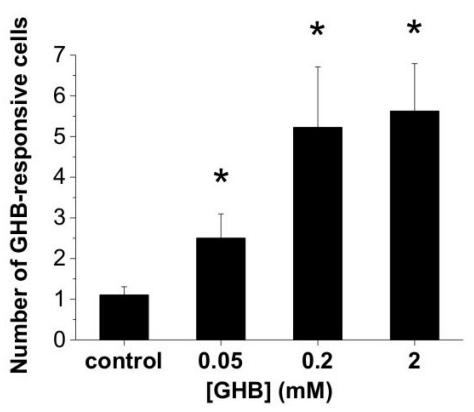

Material). (C) Representative $\mathrm{dF} / F_{0}$-time plots showing effects of $50 \mu \mathrm{M} \mathrm{GHB}$ alone (A) and with $100 \mu \mathrm{M}$ ATP puff (B). (D) Color traces correspond to the GHB-responsive cells circled in (A) and (B) while gray traces show the fluorescence changes of ATP-responsive cells. (E) Summary plot of the effects of increasing (GHB) on the number of cells showing GHB-responsive $\mathrm{Ca}^{2+}$ transients. $N=32$ (control), $N=13(0.05 \mathrm{mM}), N=9(0.2 \mathrm{mM}), N=9$ (2 mM). ${ }^{*} p<0.05$ and ${ }^{* *} p<0.01$ compared to control. from the point of application, independent of the perfusion direction (Figure 1C) with the speed of approximately $10 \mu \mathrm{m} / \mathrm{s}, 1.5$ times slower than the speed of ATP diffusion as monitored by addition of the fluorescent dye sulforhodamine 101 in the ATPcontaining pipette (Molnár et al., 2011). The waveform and speed of the signal propagation conclusively exclude the possibility that $\mathrm{Ca}^{2+}$ bursts were triggered by merely the exogenously applied ATP. Comparing the GHB- and ATP-evoked signals, the responses in the presence of GHB and ATP appeared relatively more robust than responses evoked by GHB only (Figure 1D). Summary plot of the effects of increasing (GHB) on the number of cells showing GHB-responsive $\mathrm{Ca}^{2+}$ transients indicated that similarly to SUC (Molnár et al., 2011) GHB had an $\mathrm{EC}_{50}$ value of approximately $50 \mu \mathrm{M}$, however smaller number of cells responded to GHB than to SUC, indicating lower efficacy (Figure 1E).

\section{GHB AND SUC SHAPED ATP-EVOKED CA $^{2+}$ SIGNALS IN THE SAME WAY}

We observed that the number of ATP-responsive cells decreased with increasing concentration of either SUC or GHB (Figure 2A). Moreover, the concentration dependence of the number of ATPresponsive cells were highly identical as a function of both (SUC) and (GHB; Figure 2A), suggesting a mutual target for SUC and GHB actions. Increasing [SUC] may activate this mutual target, a presumable GHB-responsive astroglial SUC receptor and consequently reduce ATP-responsiveness of astrocytes (Figures 2A,B). Furthermore, increasing [SUC] resulted in a rise of the relative abundance of SUC- and shared SUC/ATP-responsive astroglial
$\mathrm{Ca}^{2+}$ transients (Figure 2B) as well as in an increase in the number of cells showing repetitive $\mathrm{Ca}^{2+}$ dynamics (Figure 2C). The SUC-evoked repetitive $\mathrm{Ca}^{2+}$ transients (Figure 3A; Molnár et al., 2011) mimicked the GHB response dynamics described above (Figure 1D; Movie S1 in Supplementary Material), further suggesting the existence of a GHB-responsive astroglial SUC receptor. In a previous work we provided evidence on store-dependent astroglial $\mathrm{Ca}^{2+}$ transients evoked by ATP acting through the $\mathrm{G}$ protein-coupled purinergic $\mathrm{P}_{2} \mathrm{Y}_{1}$ receptor subtypes in the NAc slice (Molnár et al., 2011). Therefore, SUC- and shared SUC/ATP-responsive astroglial $\mathrm{Ca}^{2+}$ transients may suggest co-localization of GHB-responsive SUC and $\mathrm{P}_{2} \mathrm{Y}_{1}$ receptors on astrocytes.

\section{THE PRESUMED GHB-RESPONSIVE ASTROGLIAL SUC RECEPTOR WAS CLASSIFIED AS BEING INDEPENDENT OF BOTH GABA $A_{B}$ AND $\boldsymbol{N}$-METHYL-D-ASPARTATE RECEPTORS}

We supposed that similarly to GHB, its metabolite SUC also acts independently from $\mathrm{GABA}_{\mathrm{B}}$ receptors in the NAc. To verify this hypothesis we tested the effect of SUC $(2 \mathrm{mM})$ on astroglial $\mathrm{Ca}^{2+}$ transients in the NAc slice prepared from mice lacking the $\mathrm{GABA}_{\mathrm{B}}$ receptor functional subunit $1\left(\mathrm{GABA}_{\mathrm{B}} \mathrm{KO}\right)$. We found that similarly to GHB (Molnár et al., 2009), SUC-responsive $\mathrm{Ca}^{2+}$ transients were preserved in NAc slices isolated from $\mathrm{GABA}_{\mathrm{B}} \mathrm{KO}$ mice (Figure 3A). Next we asked, if NMDA receptors of the NAc slice were involved in the SUC action mechanisms. We observed that SUC responses remained unaltered in the presence of NMDA 

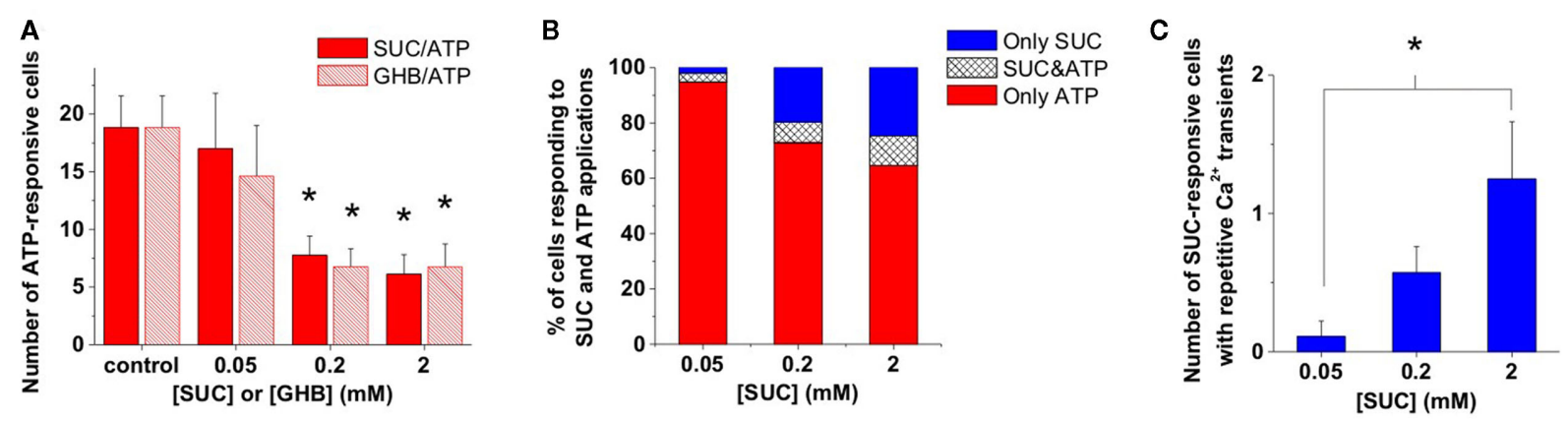

FIGURE 2 | GHB and SUC shaped ATP-evoked $\mathrm{Ca}^{2+}$ signals in the same way. (A) Average number of cells showing $\mathrm{Ca}^{2+}$ transients in response to ATP $(100 \mu \mathrm{M})$ puff-application in the presence of different concentrations of SUC or GHB. (B) Average number of cells showing $\mathrm{Ca}^{2+}$ transients during SUC or SUC plus ATP $(100 \mu \mathrm{M})$ application as a percent of the total number of cells showing $\mathrm{Ca}^{2+}$ transients during SUC or ATP application. (C) Average number of cells showing multiple $\mathrm{Ca}^{2+}$ transients during application of different SUC concentrations. $N=32$ (control), $N=13$ and $9(0.05 \mathrm{mM}), N=9$ and $21(0.2 \mathrm{mM}), N=9$ and $16(2 \mathrm{mM})$ for $\mathrm{GHB}$ and SUC, respectively, ${ }^{*} p<0.05$.
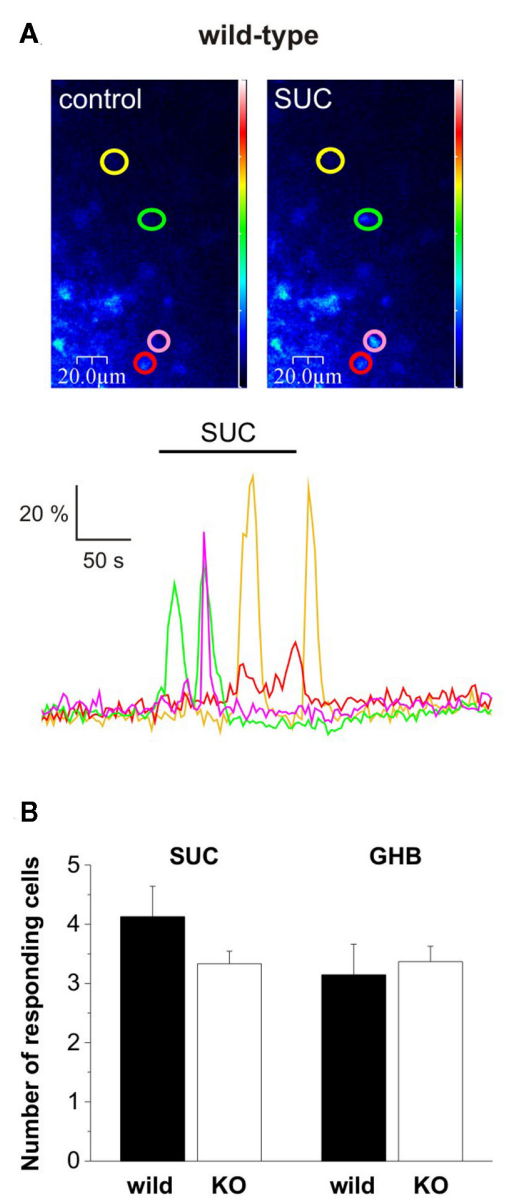

FIGURE 3 | The presumed GHB-responsive astroglial SUC receptor was classified as being independent of both $\mathrm{GABA}_{B}$ and $\boldsymbol{N}$-methyl-D-Aspartate (NMDA) receptors. (A) Pseudo-color images showing fluorescence in NAc astrocytes during control and SUC (2 mM) application in wild type and $\mathrm{GABA}_{B} \mathrm{R}$ type 1 subunit $\mathrm{KO}$ mice. Astrocytes showing SUC-evoked $\mathrm{Ca}^{2+}$ transients are circled and color-coded and the
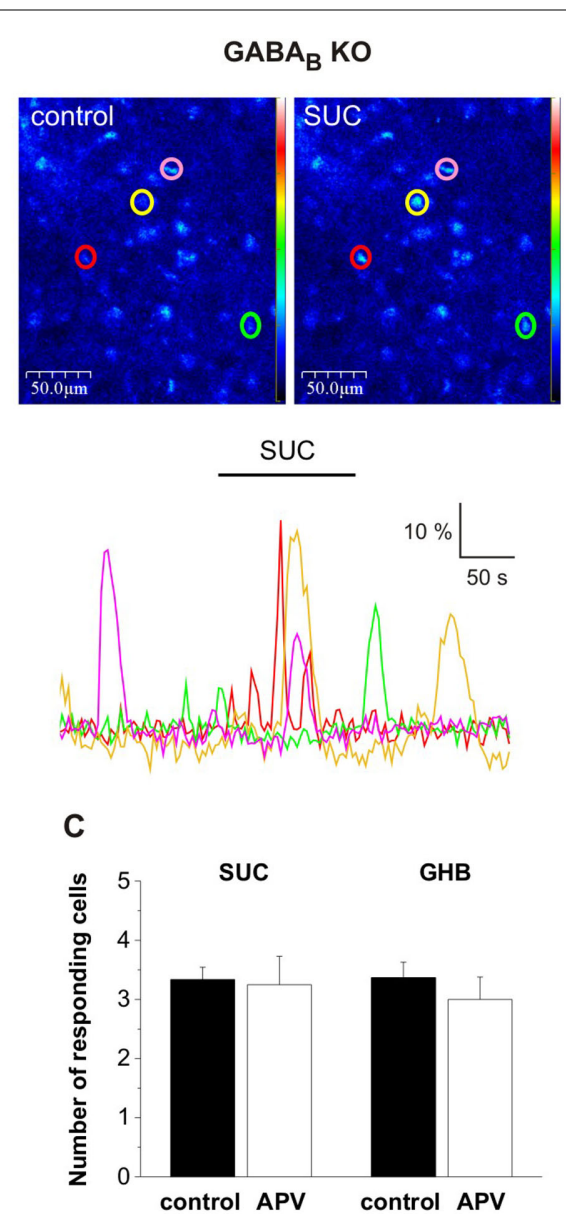

change in fluorescence is shown in $\mathrm{dF} / F_{0}$-time plots below the images. (B) Summary plots show that SUC-evoked $\mathrm{Ca}^{2+}$ transients, similarly to GHB-evoked $\mathrm{Ca}^{2+}$ transients were preserved in $\mathrm{GABA}_{B} \mathrm{R} 1 \mathrm{KO}$ mice. (C) Summary plots indicate that SUC/GHB-evoked $\mathrm{Ca}^{2+}$ transients were unaltered by the presence of NMDA receptor antagonist (2R)-amino-5-phosphonovaleric acid (APV, $20 \mu \mathrm{M}$ ). 


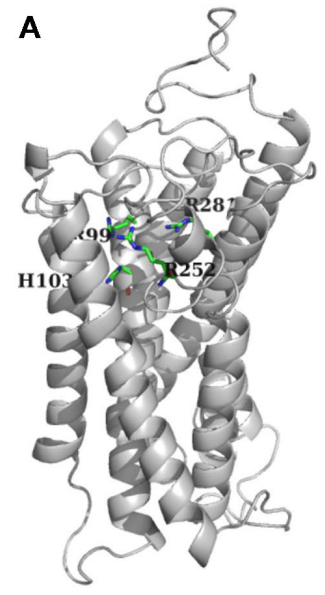

FIGURE 4 | Modeling predicted interaction of GHB with the presumed astroglial SUC receptor. (A) Stick-representation of the binding crevice residues Arg99, His103, Arg252, and Arg281 of SUCNR1 shown as gray cartoon (after He et al., 2004). (B) Residues forming the binding crevice of SUC (orange) and GHB (cyan). Residues in the $4 \AA$ vicinity

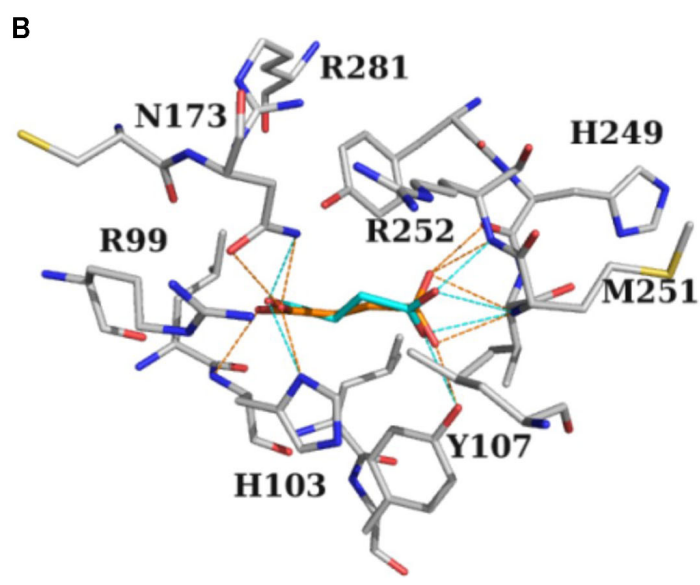

of the ligands together with Arg281 are shown in stick representation. H-bond interactions between ligands and the protein are shown as dotted lines, orange for SUC, and cyan for GHB. (A,B) Carbon atoms are gray, nitrogens, and oxygens are colored according to atom type. $\mathrm{H}$ atoms are not shown for clarity.

A
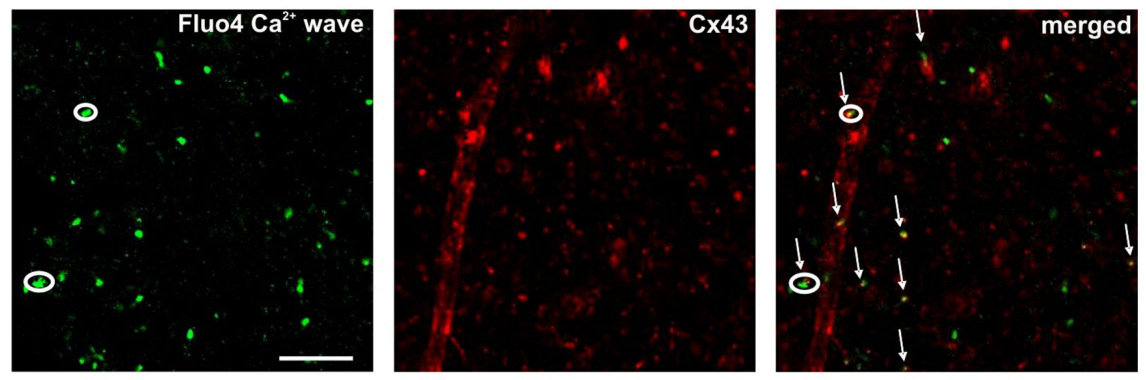

B
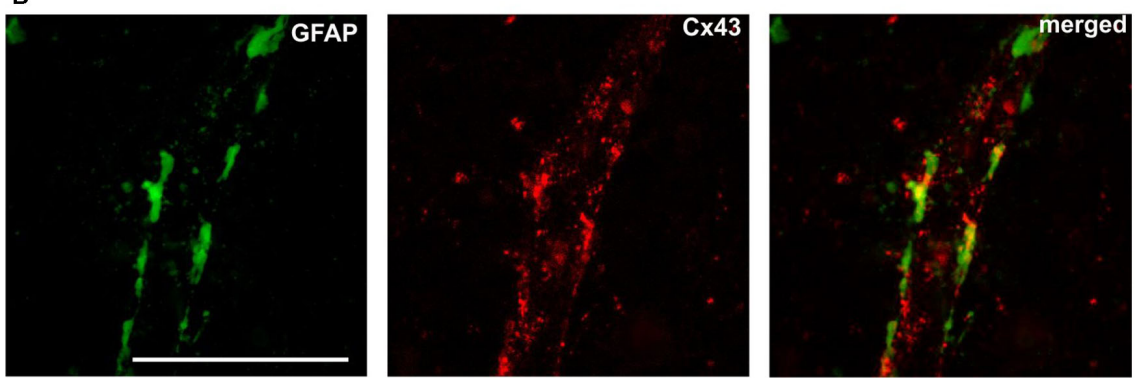

FIGURE 5 | Positioning of SUC/ATP - [(A) circles] and ATP-responsive [(A) arrows] $\mathrm{Ca}^{2+}$ transients along a vessel, identified by the appearance of $\mathrm{Cx} 43$ gap junction plaques [(A) middle and right panels). Scale bar is $50 \mu \mathrm{m}$. Higher magnification in (B) displays Cx43-immunoreactive plaques (red) interconnecting astrocytic GFAP-positive (green) end feet. receptor antagonist $(2 R)$-amino-5-phosphonovaleric acid (APV, $20 \mu \mathrm{M}$; Figure 3C). Therefore, both SUC and GHB effect on astroglial $\mathrm{Ca}^{2+}$ signals could be classified as being independent of $\mathrm{GABA}_{\mathrm{B}}$ and NMDA receptors. These data further strengthen the possibility that SUC and GHB act through a common target protein, the presumed GHB-responsive astroglial SUC receptor in the NAc.

\section{MODELING PREDICTED INTERACTION OF GHB WITH THE PRESUMED ASTROGLIAL SUC RECEPTOR}

To explore the possibility of a shared target protein for SUC and GHB actions, we used the kidney-type SUC receptor (SUCNR1:GPCR91) model structure (He et al., 2004) and simulated interactions of SUC and GHB with this protein. Docking of SUC and GHB into SUCNR1 resulted in similar ligand 
conformations occupying the same binding site. The predicted binding crevice was formed by residues R99, H103, R252, and R281 (Figure 4) in accordance with previous studies (He et al., 2004). In addition, residues T107, N173, H249, and M251 were also found to be involved in the binding of SUC and GHB (Figure 4B). Agonist SUC participated in more extensive $\mathrm{H}$-bond interactions (Figure 4B) enabling higher docking score value (35 for SUC vs. 31 for GHB). In addition, we also disclosed a previously unrecognized binding site appearing near to the entrance of the receptor, showing preference to GHB over SUC. However, being more distal to the agonist binding crevice, preferential GHB binding into this "vestibular" binding site is expected to be less effective in forming active receptor conformations, explaining the previously experienced lower efficacy of GHB.

\section{DISCUSSION}

Our previous (Molnár et al., 2006, 2008a,b, 2009, 2011) and recent (this work) findings conclusively suggest the existence of a SUC receptor in brain tissue that also recognizes GHB. Activation of the presumed brain type SUC receptor (as an analogy to SUCNR1 we reference this putative receptor as SUCBR1) by agonists SUC or GHB evokes repetitive $\mathrm{Ca}^{2+}$ transients in astrocytes independently of neuronal signaling (Molnár et al., 2009, 2011). A sub-population of SUCBR1-triggered repetitive $\mathrm{Ca}^{2+}$ transients can also be activated by ATP making $\mathrm{Ca}^{2+}$ signaling more robust. We conjecture physiological significance for the detection of these endogenous metabolites and ATP performing energy supply dependent regulation of astroglial $\mathrm{Ca}^{2+}$ bursting.

SUC shaped the astroglial $\mathrm{Ca}^{2+}$ bursting activity in different ways. Both the absolute and relative abundance of astrocytes showing ATP-evoked, $\mathrm{P}_{2} \mathrm{Y}_{1}$ receptor-mediated $\mathrm{Ca}^{2+}$ release from internal stores tended to decay with increasing [SUC]. By contrast, the astroglial SUC- and SUC/ATP-responsive $\mathrm{Ca}^{2+}$ signals were enhanced with increasing [SUC]. These findings suggest the occurrence of distinct ATP-responsive astrocytic sub-populations that can be distinguished by their responsiveness to SUC. These findings imply several mechanistic clues reasoning reduced responsiveness to ATP: (i) refilling of $\mathrm{Ca}^{2+}$ stores may take longer after activation by SUC and/or (ii) SUCBR1 may desensitize slower than P2Y 1 . These mechanistic clues, however, does not rationalize why the relative abundance of cells responsive to both SUC and ATP increases with [SUC]. Such a unique phenomenon can be explained by supposing that the presence of SUCBR1 may make desensitization of $\mathrm{P}_{2} \mathrm{Y}_{1}$ slower, also implying co-localization of SUCBR1 and $\mathrm{P}_{2} \mathrm{Y}_{1}$ receptors in the SUC/ATP-responsive sub-population of astrocytes.

Identity of SUC-sensitive GHB (Molnár et al., 2006) and GHBsensitive SUC (Molnár et al., 2008a) binding sites in rat forebrain and human NAc membrane homogenates has previously been disclosed (Molnár et al., 2008b). We have shown that drug of abuse (Wong et al., 2003, 2004), dietary supplement for body builders (Camacho et al., 2005) and brain metabolite (Bessman and Fishbein, 1963) GHB also activates store-dependent astrocytic $\mathrm{Ca}^{2+}$ transients in the brain reward area NAc (Molnár et al., 2009). Moreover, binding of GHB and SUC can be characterized by interaction with CBX (Molnár et al., 2006, 2008a,b), a blocker of gap junctions that are major players in astroglial $\mathrm{Ca}^{2+}$ wave propagation (Finkbeiner, 1992). In spite of their disclosure, molecular and cellular characterization of binding effects (Molnár et al., 2006, 2008a,b, 2009, 2011), the functional significance of astroglial SUC receptor recognizing GHB was less appreciated. Thus metabolic actions of GHB may be explained by the activation of the SUCBR1 signaling route.

Understanding of the role of $\mathrm{Ca}^{2+}$ signaling in astrocytes at neuronal and vascular interfaces through specific intercellular communication mechanisms has grown considerably in recent years (Newman and Zahs, 1997; Scemes et al., 2000; Parri et al., 2001; Matthias et al., 2003; Verkhratsky, 2006; Fiacco et al., 2007; Iadecola and Nedergaard, 2007; Sadaogopan et al., 2007; Barres, 2008; Gordon et al., 2008; Hall and Attwell, 2008; Li et al., 2008; Doengi et al., 2009; Hoogland and Kuhn, 2010; Hoogland et al., 2009; Koehler et al., 2009; Nimmerjahn, 2009; Nimmerjahn et al., 2009; Agulhon et al., 2010; Hamilton and Attwell, 2010; Xi et al., 2010). It may have significance in this respect that we observed SUC/GHB and ATP-responsive cells around NAc vessels at the end feet of astroglial processes. Representative image indicating SUCevoked $\mathrm{Ca}^{2+}$ transient in a sub-population of ATP-responsive astrocytes (Figure 5A circles and arrows, respectively) along with a vessel contoured by $\mathrm{Cx} 43$ positive plaques (Figure 5A middle and right panels). GFAP and Cx43 expression in cerebrocortical astrocyte end feet plastered at the vessel wall has previously been characterized (Simard et al., 2003). Accordingly, double immunolabelling for $\mathrm{Cx} 43$ and GFAP showed large Cx43-immunoreactive plaques interconnecting astrocytic GFAP-positive end feet along with vessels in the NAc (Figure 5B). Co-localization of SUC-responsive astrocytes and vessel wall may provide a mechanistic clue for cellular energy metabolite-responsive $\mathrm{Ca}^{2+}$ signaling activity around vessels, at the end feet of astrocyte processes interconnected by gap junctional plaques. The setting can possibly imply a role for $\mathrm{Ca}^{2+}$ signaling at the glio-vascular interface. Regulation of $\mathrm{Ca}^{2+}$ bursting through cellular energy metabolites may in turn provide a mechanism for the control of astrocyte activation and will therefore benefit from further study in awake, behaving animal.

\section{ACKNOWLEDGMENTS}

This work was supported by TECH-09-A1-2009-0117 and CRCHAS-2009-Nanotransport grants. The authors thank Erzsébet Kútiné-Fekete for excellent technical assistance.

\section{SUPPLEMENTARY MATERIAL}

The Movie S1 for this article can be found online at http:// www.frontiersin.org/neuroenergetics/10.3389/fnene.2011.00007/ abstract

Movie S1 | File name: 3-31-29_PM-diff.avi. $\mathrm{Ca}^{2+}$ signaling evoked by GHB and ATP in the acute NAc slice from the rat brain. Movie of time measurement showing GHB $(50 \mu \mathrm{M})$ and ATP $(100 \mu \mathrm{M})$ application onto a Fluo-4 AM loaded acute, $300 \mu \mathrm{m}$ thick NAc slice. GHB was applied between 0 and $2 \mathrm{~min}$ in the perfusion buffer. ATP was applied for $60 \mathrm{~s}$ starting from $1.5 \mathrm{~min}$ through a glass micropipette right above the tissue surface. Image acquisition frequency was $2 \mathrm{~s}$ in depth of $\sim 25 \mu \mathrm{m}$ from the slice surface. The background fluorescence (first frame) was subtracted from all subsequent frames in the image stack. The resulting images were false colored (more red pixels represent higher $\mathrm{dF} / F_{0}$ values) and converted to avi file by ImageJ 1.44 image processing and analysis software. 


\section{REFERENCES}

Agulhon, C., Fiacco, T. A., and McCarthy, K. D. (2010). Hippocampal short- and long-term plasticity are not modulated by astrocyte $\mathrm{Ca} 2^{+}$ signaling. Science 327, 1250-1254.

Anderson, C. M., Bergher, J. P., and Swanson, R. A. (2004). ATP-induced ATP release from astrocytes. $\mathrm{J}$. Neurochem. $88,246-256$.

Andriamampandry, C., O. Taleb, O., Kemmel, V., Humbert, J. P., Aunis, D., and M. Maitre, M. (2007). Cloning and functional characterization of a gamma-hydroxybutyrate receptor identified in the human brain. FASEB J. 21, 885-895.

Andriamampandry, C., Taleb, O., Viry, S., Muller, C., Humbert, J. P., Gobaille, S., Aunis, D., and Maitre, M. (2003). Cloning and characterization of a rat brain receptor that binds the endogenous neuromodulator gamma-hydroxybutyrate (GHB). FASEB J. 17, 1691-1693.

Barres, B. A. (2008). The mystery and magic of glia: a perspective on their roles in health and disease. Neuron 60, 430-440.

Barry, V. A., and Cheek, T. R. (1994). Extracellular ATP triggers two functionally distinct calcium signalling pathways in PC12 cells. J. Cell Sci. 107, 451-462.

Beierlein, M., and Regehr, W. G. (2006). Brief bursts of parallel fiber activity trigger calcium signals in Bergmann glia. J. Neurosci. 26, 6958-6967.

Berridge, K. C., and Kringelbach, M. L. (2008). Affective neuroscience of pleasure: reward in humans and animals. Psychopharmacology 199, 457-480.

Bessman, S. P., and Fishbein, W. N. (1963). Gamma-hydroxybutyrate, a normal brain metabolite. Nature 200, 1207-1208.

Camacho, A., Matthews, S. C., Murray, B., and Dimsdale, J. E. (2005). Use of GHB compounds among college students. Am. J. Drug Alcohol Abuse 31, 601-607.

D’Ascenzo, M., Fellin, T., Terunuma, M., Revilla-Sanchez, R., Meaney, D. F., Auberson, Y. P., Moss, S. J., and Haydon, P. G. (2007). mGluR5 stimulates gliotransmission in the nucleus accumbens. Proc. Natl. Acad. Sci. U.S.A. 104, 1995-2000.

Doengi, M., Hirnet, D., Coulon, P., Pape, H. P., Deitmer, J. W., and Lohr, C. (2009). GABA uptake-dependent $\mathrm{Ca}^{+}{ }^{+}$signaling in developing olfactory bulb astrocytes. Proc. Natl. Acad. Sci. U.S.A. 106, 17570-17575.

Fiacco, T. A., Agulhon, C., Taves, S. R., Petravicz, J., Casper, K. B., Dong, X., Chen, J., and McCarthy, K. D. (2007). Selective stimulation of astrocyte calcium in situ does not affect neuronal excitatory synaptic activity. Neuron 54, 611-626.

Finkbeiner, S. (1992). Calcium waves in astrocytes-filling in the gaps. Neuron 8, 1101-1108.

Fischer, W., Appelt, K., Grohmann, M., Franke, H., Nörenberg, W., and Illes, P. (2009). Increase of intracellular $\mathrm{Ca}^{+}$by $\mathrm{P} 2 \mathrm{X}$ and $\mathrm{P} 2 \mathrm{Y}$ receptor-subtypes in cultured cortical astroglia of the rat. Neuroscience 160, 767-783.

Forni, L. G., McKinnon, W., Lord, G. A., Treacher, D. F., Peron, J. M., and Hilton, P. J. (2005). Circulating anions usually associated with the Krebs cycle in patients with metabolic acidosis. Crit. Care 9, 591-595.

Gordon, G. J. R., Choi, H. B., Rungta, R. L., Ellis-Davies, G. C. R., and MacVicar, B. A. (2008). Brain metabolism dictates the polarity of astrocyte control over arterioles. Nature 456, 745-750.

Hall, C. N., and Attwell, D. (2008). Neuroscience: brain power. Nature 456, 715-716.

Hamilton, N. B., and Attwell, D. (2010). Do astrocytes really exocytose neurotransmitters? Nat. Rev. Neurosci. 11, 227-238.

He, W., Miao, F. J. P., Lin, D. C. H., Schwandner, R. T., Wang, Z., Gaol J, Chen, J. L., Tian, H., and Ling, L. (2004). Citric acid cycle intermediates as ligands for orphan Gprotein-coupled receptors. Nature 429, 188-193.

Helmetag, V., Samel, S. A., Thomas, M. G., Marahiel, M. A., and Essen, L. O. (2009). Structural basis for the erythro-stereospecificity of the L-arginine oxygenase $\mathrm{VioC}$ in viomycin biosynthesis. FEBS J. 276, 3669-3682.

Hirase, H., Qian, L., and Barthó P, Buzsáki G. (2004). Calcium dynamics of cortical astrocytic networks in vivo. PLoS Biol. 2, 0494-0499. doi:10.1371/journal.pbio.0020096

Hochachka, P. W., and Dressendorfer, R. H. (1976). Succinate accumulation in man during exercise. Eur. J. Appl. Physiol. Occup. Physiol. 35, 235-242.

Hoogland, T. M., and Kuhn, B. (2010). Recent developments in the understanding of astrocyte function in the cerebellum in vivo. Cerebellum 9, 264-271.

Hoogland, T. M., Kuhn, B., Gobel, W., Huang, W., Nakai, J., Helmchen, F., Flint, J., and Wang, S. S. (2009). Radially expanding transglial calcium waves in the intact cerebellum. Proc. Natl. Acad. Sci. U.S.A. 106, 3496-3501.
Iadecola, C., and Nedergaard, M. (2007). Glial regulation of the cerebral microvasculature. Nat. Neurosci. 10, 1369-1376.

Kaupmann, K., Cryan, J. F., Wellendorph, P., Mombereau, C., Sansig, G., Klebs, K., M. Schmutz, M., Froestl, W., van der Putten, H., Mosbacher, J., Bräuner-Osborne, H., Waldmeier, P. B., and Bettler, B. (2003). Specific gamma-hydroxybutyratebinding sites but loss of pharmacological effects of gammahydroxybutyrate in GABA(B) (1)deficient mice. Eur. J. Neurosci. 18, 2722-2730.

Koehler, R. C., Roman, R. J., and Harder, D. R. (2009). Astrocytes and the regulation of cerebral blood flow. Trends Neurosci. 32, 160-169.

Krebs, H. A. (1950). Chemical composition of blood plasma and serum Annu. Rev. Biochem. 19, 409-430.

Kushnir, M. M., Komaromy-Hiller, G. Shushan, B., Urry, F. M., and Roberts, W. L. (2001). Analysis of dicarboxylic acids by tandem mass spectrometry. High-throughput quantitative measurement of methylmalonic acid in serum, plasma, and urine. Clin. Chem. 47, 1993-2002.

Li, A., Xi, Q., Umstot, E. S., Bellner, L., Schwartzman, M. L., Jaggar, J. H., and Leffler, C. W. (2008). Astrocytederived $\mathrm{CO}$ is a diffusible messenger that mediates glutamate-induced cerebral arteriolar dilation by activating smooth muscle cell KCa channels. Circ. Res. 102, 234-241.

Li, Y., Holtzclaw, L. A., and Russell, J. T. (2001). Müller cell $\mathrm{Ca} 2^{+}$waves evoked by purinergic receptor agonists in slices of rat retina. J. Neurophysiol. 85, 986-994.

MacMillan, V. (1980a). Sequential alterations of cerebral carbohydrate metabolism associated with gammahydroxybutyrate. Brain Res. 183, 123-134.

MacMillan, V. (1980b). Effects of gamma-hydroxybutrate and gamma-butyrolactone on cerebral energy metabolism during exposure and recovery from hypoxemia-oligemia. Stroke 11 271-277.

Mamelak, M. (1989). Gamma hydroxybutyrate: an endogenous regulator of energy metabolism. Neurosci. Biobehav. Rev. 13, 187-198.

Matthias, K., Kirchhoff, F., Seifert, G. Huttmann, K., Matyash, M., Kettenmann, H., and Steinhauser, C. (2003). Segregated expression of AMPA-type glutamate receptors and glutamate transporters defines distinct astrocyte populations in the mouse hippocampus. J. Neurosci. 23, 1750-1758.
Molnár, T., Antal, K., Nyitrai, G., and Emri, Z. (2009). Gammahydroxybutyrate (GHB) induces GABAB receptor independent intracellular $\mathrm{Ca}^{+}{ }^{+}$transients in astrocytes, but has no effect on GHB or GABAB receptors of medium spiny neurons in the nucleus accumbens. Neuroscience 162, 268-281.

Molnár, T., Barabás, P., Héja, L., Fekete, E. K., Lasztóczi, B., Szabó P, Nyitrai, G., Simon-Trompler, E., Hajós F, Palkovits, M., and Kardos, J. (2008a). Gamma-hydroxybutyrate binds to the synaptic site recognizing succinate monocarboxylate: a new hypothesis on astrocyteneuron interaction via the protonation of succinate. J. Neurosci. Res. 86, 1566-1576.

Molnár, T., Visy, J., Simon, A., Moldvai, I., Temesvári-Major, E., Dörnyei, G., Kútiné Fekete, E. K. and Kardos, J. (2008b) Validation of high-affinity binding sites for succinic acid through distinguishable binding of gamma-hydroxybutyric acid receptor-specific NCS 382 antipodes. Bioorg. Med. Chem. Lett. 18, 6290-6292.

Molnár, T., Dobolyi, Á., Nyitrai, G., Barabás, P., Héja, L., Emri, Z., Palkovits, M., and Kardos, J. (2011). Calcium signals in the nucleus accumbens: activation of astrocytes by ATP and succinate. BMC Neurosci. 12, 96. doi:10.1186/1471-2202-12-96

Molnár, T., Fekete, E. K., Kardos, J., Simon-Trompler, E., Palkovits, M., and Emri, Z. (2006). Metabolic GHB precursor succinate binds to gamma-hydroxybutyrate receptors: characterization of human basal ganglia areas nucleus accumbens and globus pallidus. J. Neurosci. Res. 84, 27-36.

Newman, E. A., and Zahs, K. R. (1997). Calcium waves in retinal glial cells. Science 275, 844-847.

Nimmerjahn, A. (2009). Astrocytes going live: advances and challenges. J. Physiol. 587, 1639-1647.

Nimmerjahn, A., Mukamel, E. A., and Schnitzer, M. J. (2009). Motor behavior activates bergmann glial networks. Neuron 62, 400-412.

Nordmann, J., and Nordmann, R. (1961). Organic acids in blood and urine. Adv. Clin. Chem. 4, 53-120.

Palczewski, K., Kumasaka, T., Hori, T., Behnke, C. A., Motoshima, H., Fox, B. A., Le Trong, I., Teller, D. C., Okada, T., Stenkamp, R. E., Yamamoto, M., and Miyano, M. (2000). Crystal structure of rhodopsin: a G proteincoupled receptor. Science 289, 739-745. 
Parri, H. R., Gould, T. M., and Crunelli, V. (2001). Spontaneous astrocytic $\mathrm{Ca}_{2}{ }^{+}$oscillations in situ drive NMDAR-mediated neuronal excitation. Nat. Neurosci. 8, 803-812.

Piet, R., and Jahr, C. E. (2007). Glutamatergic and purinergic receptormediated calcium transients in Bergmann glial cells. J. Neurosci. 27, 4027-4035.

Porter, J. T., and McCarthy, K. D. (1996). Hippocampal astrocytes in situ respond to glutamate released from synaptic terminals. J. Neurosci. 16, 5073-5081.

Prosser, H. M., Gill, C. H., Hirst, W. D., Grau, E., Robbins, M., Calver, A., Soffin, E. M., Farmer, C. E., Lanneau, C., Gray, J., Schenck, E., Warmerdam, B. S., Clapham, C., Reavill, C., Rogers, D. C., Stean, T., Upton, N., Humphreys, K., Randall, A., Geppert, M., Davies, C. H., and Pangalos, M. N. (2001). Epileptogenesis and enhanced prepulse inhibition in GABA(B1)-deficient mice. Mol. Cell. Neurosci. 17, 1059-1070.

Rumigny, J. F., Maitre, M., Cash, C., and Mandel, P. (1981). Regional and subcellular localization in rat brain of the enzymes that can synthesize gamma-hydroxybutyric acid. J. Neurochem. 36, 1433-1438.
Sadagopan, N., Li, W., Roberds, S. L., Major, T., Preston, G. M., Yu, Y., and Tones, M. A. (2007). Circulating succinate is elevated in rodent models of hypertension and metabolic disease. Am. J. Hypertens. 20, 1209-1215.

Sali, A., and Blundell, T. L. (1993). Comparative protein modeling by satisfaction of spatial restraints. J. Mol. Biol. 234, 779-815.

Scemes, E., Suadicani, S. O., and Spray, D. C. (2000). Intercellular communication in spinal cord astrocytes: fine tuning between gap junctions and P2 nucleotide receptors in calcium wave propagation. J. Neurosci. 20, 1435-1445.

Schuler, V., Lüscher, C., Blanchet, C., Klix, N., Sansig, G., Klebs, K., Schmutz, M., Heid, J., Gentry, C., Urban, L., Fox, A., Spooren, W., Jaton, A. L., Vigouret, J., Pozza, M., Kelly, P. H., Mosbacher, J., Froestl, W., Käslin, E., Korn, R., Bischoff, S., Kaupmann, K., van der Putten, H., and Bettler, B. (2001). Epilepsy, hyperalgesia, impaired memory and loss of pre and postsynaptic $\mathrm{GABA}(\mathrm{B})$ responses in mice lacking $\operatorname{GABA}(\mathrm{Z}(1))$. Neuron 31, 47-58.

Simard, M., Arcuino, G., Takano, T., Liu, Q., and Nedergaard, M. (2003). Signaling at the gliovascular interface. J. Neurosci.23, 9254-9262.

Stout, C. E., Costantin, J. L., Naus, C. C., and Charles, A. C. (2002) Intercellular calcium signaling in astrocytes via ATP release through connexin hemichannels. J. Biol. Chem. 277, 10482-10488.

Takata, N., and Hirase, H. (2008). Cortical layer 1 and layer $2 / 3$ astrocytes exhibit distinct calcium dynamics in vivo. PLoS ONE 3, e2525. doi:10.1371/journal.pone.0002525

Verkhratsky, A. (2006). Glial calcium signaling in physiology and pathophysiology. Acta Pharmacol. Sin. 27, 773-780.

Wong, C. G., Bottiglieri, T., and Snead, OC. (2003). GABA, gammahydroxybutyric acid and neurological diseases. Ann. Neurol. 54 S3-S12.

Wong, C. G., Gibson, K. M., and Snead, O. C. (2004). From the street to the brain: neurobiology of the recreational drug gammahydroxybutyric acid. Trends Pharmacol. Sci. 25, 29-34.

Xi, Q., Umstot, E., Zhao, G., Narayanan, D., Leffler, C. W., and Jaggar, J. H. (2010). Glutamate regulates $\mathrm{Ca}^{+}$ signals in smooth muscle cells of newborn piglet brain slice arterioles through astrocyte- and heme oxygenase-dependent mechanisms.
Am. J. Physiol. Heart Circ. Physiol. 298, 562-569.

Zur Nieden, R., and Deitmer, J. W. (2006). The role of metabotropic glutamate receptors for the generation of calcium oscillations in rat hippocampal astrocytes in situ. Cereb. Cortex 16, 676-687.

Conflict of Interest Statement: The authors declare that the research was conducted in the absence of any commercial or financial relationships that could be construed as a potential conflict of interest.

Received: 22 October 2011; accepted: 25 November 2011; published online: 12 December 2011.

Citation: Molnár T, Héja L, Emri Z, Simon Á, Nyitrai G, Pál I and Kardos $J$ (2011) Activation of astroglial calcium signaling by endogenous metabolites succinate and gamma-hydroxybutyrate in the nucleus accumbens. Front. Neuroenerg. 3:7. doi: 10.3389/fnene.2011.00007 Copyright @ 2011 Molnár, Héja, Emri, Simon, Nyitrai, Pál and Kardos. This is an open-access article distributed under the terms of the Creative Commons Attribution Non Commercial License, which permits non-commercial use, distribution, and reproduction in other forums, provided the original authors and source are credited. 